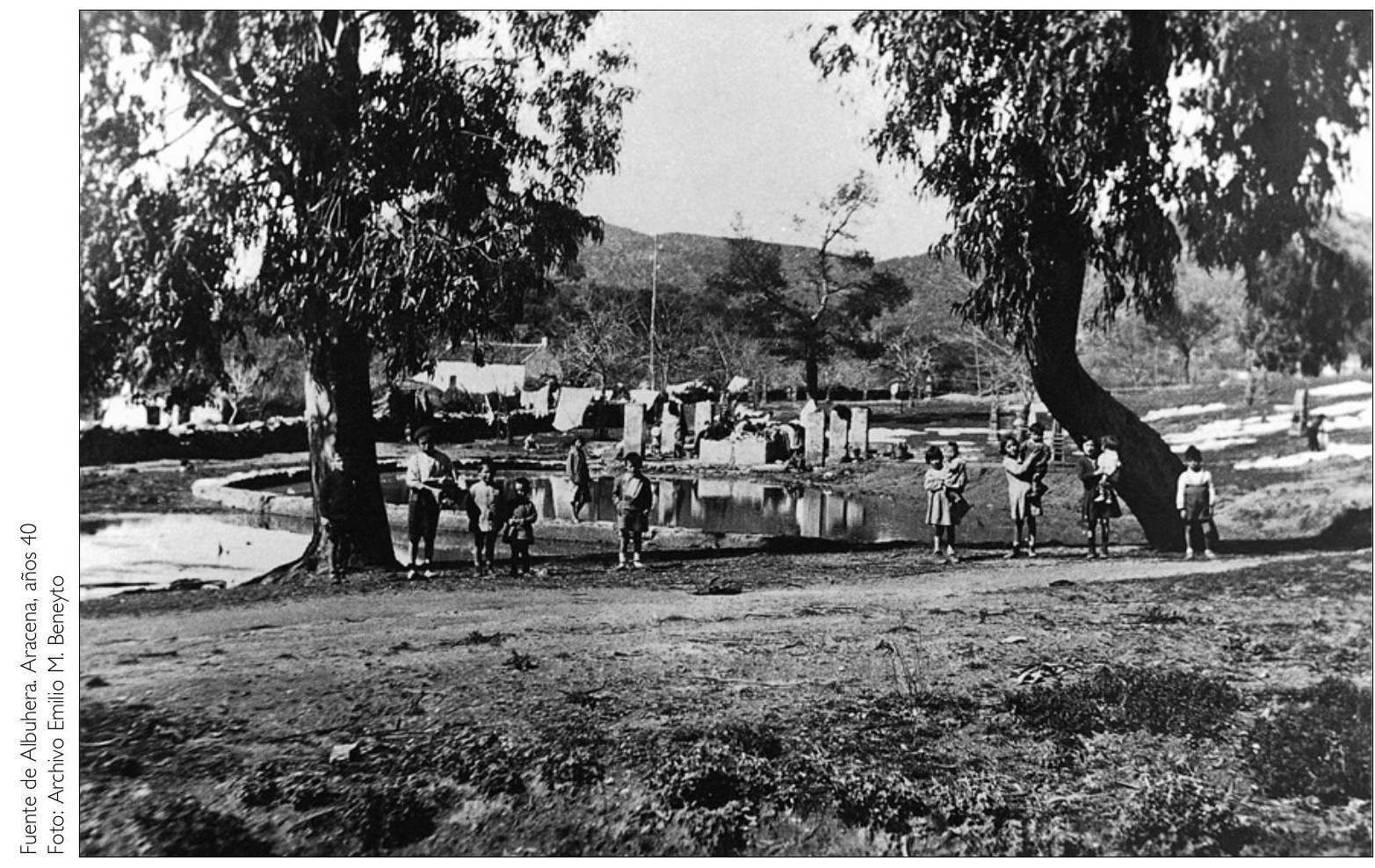

\title{
Arquitectura del Agua: \\ el Espacio del Agua
}

Pedro A Cantero

Antropólogo

Al colectivo Enteoria, a mis compañeros del GISAP, y al pueblo de Pegalajar, con quienes comparto un pensar del espacio
I

\section{"D} mar muy pobremente el ser de la cosa. En el curso del pensamiento occidental, resultó que se representara la cosa como una $X$ desconocida, afectada por cualidades percibibles. Desde esta perspectiva, todo lo que pertenece a la esencia unificadora de esta cosa aparece como una añadidura introducida por una interpretación posterior".

Este pensamiento de Heidegger (1994. p. I 35)' a propósito de un puente, como ejemplo de toda construcción, me parece significativo para encabezar la reflexión sobre la arquitectura del agua y su espacio. La construcción se toma, de ordinario, al pie de la Técnica², sin tener en cuenta lo fundamental: construir im- 
plica habitar. Toda construcción debe tener como fin ser habitada, aun no siendo alojamiento, sí debe ser morada. El hombre la ocupa aunque no habite, "si habitar significa únicamente tener alojamiento." Hago mía la idea de Heidegger que concibe el habitar como "el fin que preside el construir". (Ibídem, p. 128)

Si la arquitectura está destinada a "ser" habitada, se puede decir que toda arquitectura que perdió su razón de "ser" está condenada a perecer, está condenada a degradarse rápidamente 3 . Mientras "era" se mantenía, primaba como valor habitar-la, privilegiando reparaciones útiles en detrimento del resto. Se mantenía por "ser" habitada, creaba lugart.

Si toda construcción implica espacio, no siempre construir basta para crear lugar. Heidegger dice que "el lugar es lo que reúne en sí el ser de una cosa" (Der Satz vom Grund, p. 106)5, pero el lugar no existe antes del uso, si la construcción crea un espacio de habitabilidad, habitar crea lugar. Así al inventariar un edificio no se puede perder de vista la estrecha relación entre la construcción y el sitio, entendido como espacio de sociabilidad. Desplazar un edificio sin recrear lugar es hacerlo fósil, es firmar su cosificación estéril, se le condena a la muerte sin objeto, a la degradación irremediable.

Cuando se habitaba la arquitectura del agua, edificio y paraje formaban cuerpo como un ser vivo. Tratándose de las fuentes, es cierto que estaban protegidas por una reglamentación estricta, si almotacenes, canteros, regadores, aguañones, fontaneros, poceros, ... constituían un conjunto de oficios destinados al cuidado de la frágil y compleja fábrica, no es menos cierto que los mismos azacanes y usuarios, que "habitaban" el espacio del agua diariamente, lo mantenían con su presencia. No por que el uso diario no los degradase, sino por que parecía necesario su mantenimiento, tanto por servir para el abastecimiento de la población, como por ser punto de intensa sociabilidad.

La fragilidad de esta arquitectura le es intrínseca, cierto, por estar destinada al transporte de un elemento escurridizo que causaba frecuentes escapes y numerosos daños -las agua finas la corroían y las duras provocaban concreciones que terminaban por obturar los conductos-, pero no menos cierto, por los desperfectos que el uso social le imponía: el constante acarreo, y el trajín de reuniones, juegos y bromas, producían desgaste y suciedad, degradaban el aspecto y dañaban la estructura.

Pese a todo esto, no hay peor uso que el desuso. Si el uso causa daños en un edificio, el desuso lo condena al abandono. "Deshabitar" un edificio es condenarlo, pretender salvaguardar un edificio sin atribuirle razón de "ser" es una incongruencia.

Ahora bien, si transformar un antiguo hospital en parlamento, en prestigioso centro de arte, o en frecuentado centro universitario, es algo posible, ¿qué razón de "ser" puede atribuírsele a un lavadero abandonado? Lo mismo puede decirse de un abrevadero o de una alberca, de un arca, o de un acueducto. ¿Qué habitabilidad puede atribuirse a este tipo de construcciones para permitir su mejor mantenimiento?

Me diréis, qué interés tiene esta reflexión y este cuestionamiento a la hora de inventariar. El interés de comprender la función que le hizo y el sistema del que forma parte, para catalogarlo correctamente; no perder de vista el espacio de todo edificio y, llegado el caso, proponer una restauración adecuada para su habitabilidad futura.

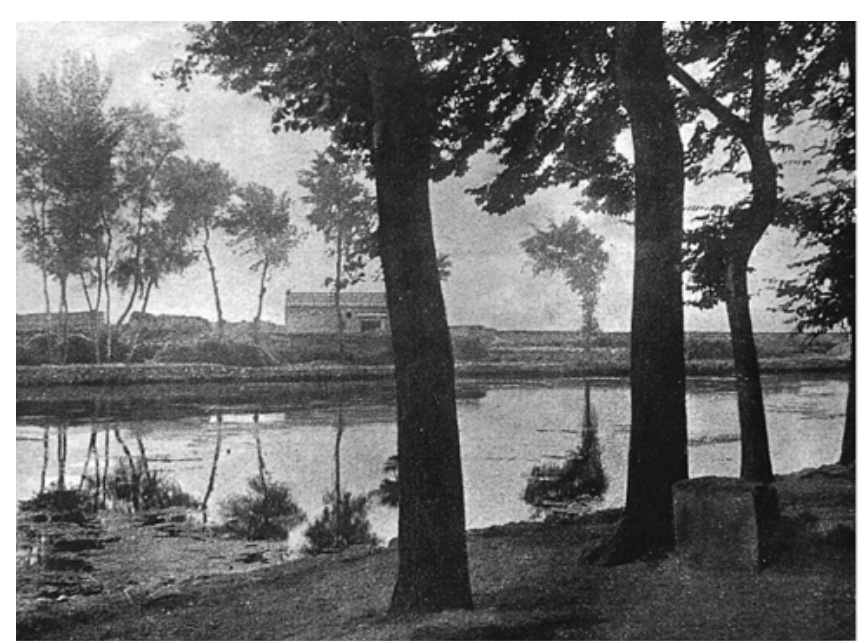

Fig. I Charca de Pegalajar. Años 20. En otros tiempos llamada Balsa, Laguna, Presa y estanque.

Si la casi totalidad de las fuentes tenían la función de abastecimiento, ahí no se limitaba su uso práctico, abrevadero, lavadero, regadío, fuerza de energía, completaban el cuadro. Muchas de ellas poseían un indiscutible valor ornamental y algunas se veían enriquecidas por una carga simbólica. Todo eso llevaba implícito el que fuesen un lugar de sociabilidad central.

Por esas razones considero importante desarrollar dos temas: el relacionado con el objeto y el que revela su razón de ser. De ahí que centre esta reflexión sobre las preguntas siguientes: Cuál es el edificio central, cuáles son los edificios subsidiarios. Qué lugar formaban, cómo se les habitaba, cuál era el sistema complejo en el que se inscribían. Qué era la cultura del agua. Qué función cumplían las fuentes. Qué valores las investían. Qué usos y valores les quedan. Amén de los problemas que esto conlleva.

El agua, en la sociedad de antaño, representaba uno de los elementos capitales de la cultura, en ella se reunía lo vital y lo accesorio, lo sagrado y lo utilitario, de ella dependían rituales, y vida doméstica, la economía y el placer. El valor social de la fuente radica en su utilidad plural. En ella se reúne lo práctico y lo simbólico, el viaje y la estancia, lo agrícola, lo urbano, y lo doméstico. Si la descripción de la construcción y de las construcciones que con ella forman lugar, parece ser la primera respuesta, también lo es la descripción del sitio y sus usos sociales. Toda fuente forma sistema y es en esa pluralidad de funciones donde radica su mayor atracción. No sólo abastece a una pobla- 


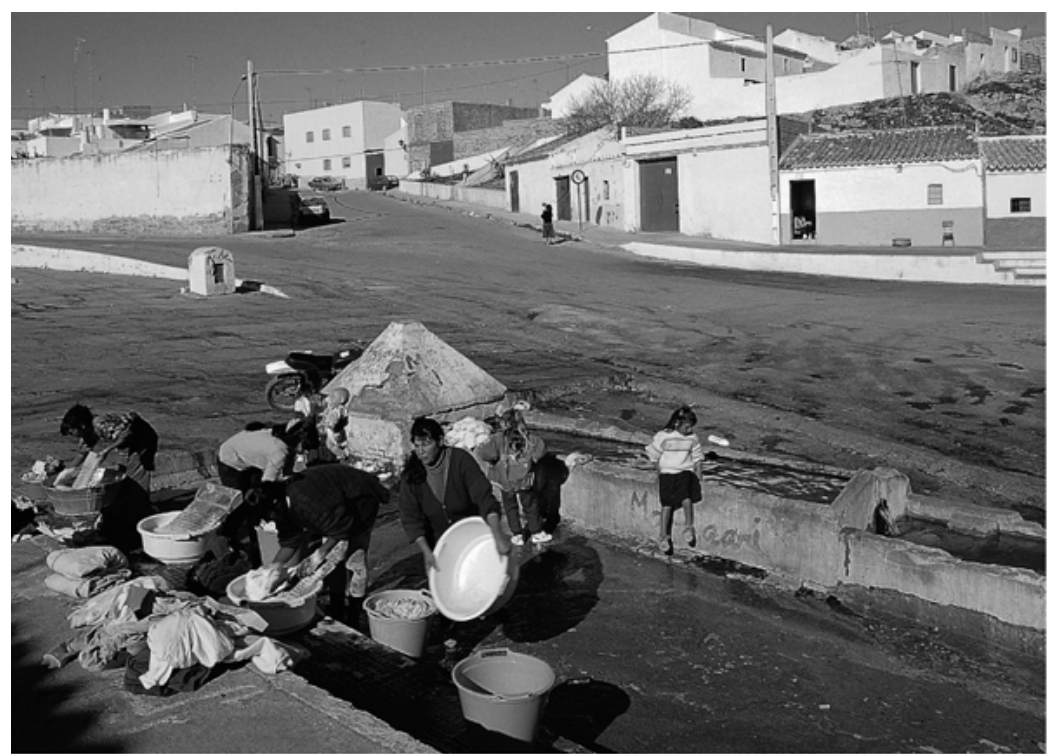

Fig. 2 La fuente vieja. La Puebla de Cazalla. Foto: Javier Andrada

Fig. 3 La fuente vieja de Aznalcollar. Foto: Javier Andrada

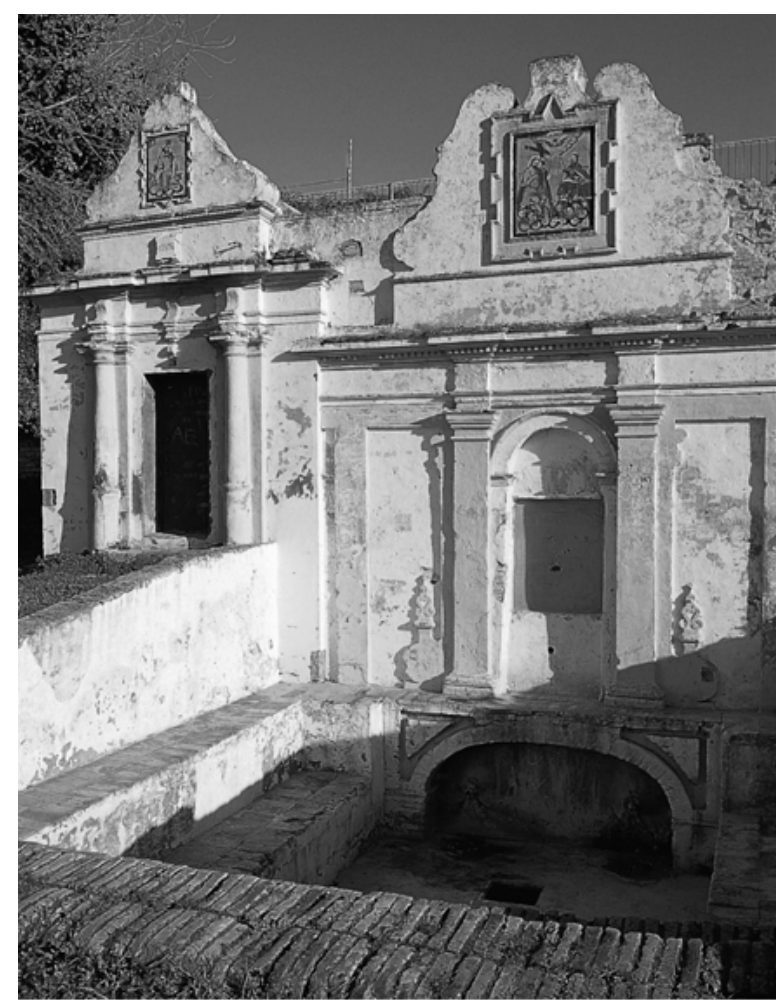

ción del elemento vital, sino que le sirve de símbolo, es ornamento, y espacio de sociabilidad mixta. Permite reunirse a un público diverso, en una misma área, y si ya no es algo obvio, es imprescindible tener en cuenta que facilitaba el encuentro entre hombres y mujeres, en una sociedad en la que la separación de géneros se inscribía en el espacio.

Era frecuente encontrar en la fuente principal de un pueblo una referencia a lo sagrado, una pieza destinada al abastecimiento humano, otra para abrevar el ganado, una cuarta para lavar la ropa y un elemento final como cabeza de almacenamiento destinado al regadío o para suministrar fuerza de energía. Además del arca y del sistema de conducción con sus atanores, respiraderos y aclaradores, que la precede, la fuente es el elemento central del conjunto. Cerca de ella, cuando no están confundidos, existe una imagen sagrada o una ermita, un abrevadero es el siguiente eslabón de la cadena, y algo más distante, un lavadero y una alberca, así como una serie de acequias y otras edificaciones que la prolongan. Es también frecuente que la fuente organizase el espacio urbano y estuviese al origen de una plaza o de un planteamiento urbanístico. Me parece importante tener en cuenta esta pluralidad de elementos para hacer un inventario, tanto si se quiere conservar la globalidad, como si se privilegia uno solo.

En cuanto a la sociabilidad me parece necesario recordar la diversa población que se reunía, tanto en las fuentes de veredas como en las urbanas. En los caminos como en los pueblos, los abrevaderos, así como las albercas de riego, fueron lugares masculinos por excelencia, en ellos se cruzaban gañanes, arrieros, hortelanos, buhoneros, aguadores, tratantes... , lo cual daba lugar a encuentros ordinarios o excepcionales, a fricciones, tratos, arreglos o simples saludos e intercambios sobre el estado del ganado, del cielo, o de la tierra. En las fuentes urbanas, dos espacios sirvieron de ágora a las mujeres, donde se enconaban o solucionaban conflictos, se daba libre curso a la palabra: la fuente y los lavaderos. Ambos se hallaban a menudo dentro de recintos bien marcados, la fuente podía resultar un "salón" con gradas y bancos que permitían el acceso y la espera, en cuanto a los lavaderos, se fueron enriqueciendo con el paso del tiempo con elementos funcionales que facilitaban la estancia y las tareas de lavado. Si en ciertos momentos la faena primaba sobre el resto, había otros en los que ir a la fuente servía de pretexto para encontrarse. La sociabilidad que generaban dio a algunas una importancia capital en el ordenamiento urbano y ocurrió con frecuencia que de hallarse en los arrabales pasaron a encontrarse, con el paso de los años, en el centro de la población y se convirtieran en uno de sus mejores ornatos; tanta era la atracción que ejercían sobre la gente.

Comprender el conjunto permite saber lo que sobra o falta para que este permanezca vivo, no comprenderlo puede derivar en la creación de un espacio baldío, en un "no-lugar". Me parece importante no olvidarlo a la hora de inventariar la arquitectura de toda fuente, pues es corriente desdeñar edificios, o elementos capitales, al no comprender su razón de "ser".

Si los motivos que están a la base de todo inventario son los de conocer, proteger y valorizar nuestros bienes culturales, pierden sentido si no se tiene en cuenta la totalidad de un edificio, una fuente cortada del resto es un residuo sin gran valor. Es cierto que no resuelven necesariamente otro problema crucial: qué usos y sobre todo qué valores les quedan a las fuentes? cuestiones que el inventario no puede remediar. Conviene a los políticos y en último término a los ciudadanos el deber de reinvestirlo, convertir la construcción en un lugar, que, como veremos en algún ejemplo, es siempre 
posible si se entiende la necesidad de que toda cosa responda a una razón de "ser".

Si un inventario no puede suplir a una acción ciudadana para "revalorizar" un edificio, esto no quita para afirmar que bien inventariar está a la base de toda conservación digna. Un inventario mal hecho sirve de poco, la utilidad del inventario radica en su riqueza, en el peor de los casos si un inventario es bueno con él se ha salvado la memoria, y a veces basta eso para hacer posible su renacimiento futuro6.

El inventario de una arquitectura del agua debe contener informaciones breves sobre:

- la localización precisa del conjunto, así como un plano de situación.

- la descripción del lugar, entorno y espacio de sociabilidad que genera.

- la descripción de cada edificio: fuente y recinto, arca, ermita, abrevadero, lavaderos, alberca. Teniendo en cuenta los materiales, estructura, técnica, y sus diferentes elementos, captación, conducción, respiraderos y aclaraderos, frontones, pilares, imágenes sagradas o profanas, exorno (...).

- síntesis del sistema de acequias, sistema de riego, y otros eslabones de la cadena del agua: presas, fábricas, molinos, etc.

- su historia: origen, autor, modificaciones.

- los usos prácticos, simbólicos y ornamentales.

- el estado de conservación.

- intervenciones que parecen necesarias?

Por lo que concierne al inventario de las fuentes públicas que se hizo en Andalucía en los años ochenta, me parece oportuno anotar que fue mal diseñado, no se acertó en la misión y no se difundió su resultado. Las fichas que sirvieron de modelo fueron poco pensadas y se encomendó la misión a técnicos que no percibieron la visión del conjunto. Por un lado consignas de inventario muy pobres y por otro agentes demasiado especializados, acabando el resultado en un rincón sin uso. Se dispuso de unas fichas mediocres, muy poco precisas, demasiado abiertas, dejando a la apreciación de cada experto las anotaciones que pudieran enriquecer el inventario. En el mejor de los casos, se anotaron los elementos más aparentes, dejando de lado aspectos imprescindibles para la comprensión del edificio. No se tuvieron en cuenta los aspectos sociales del agua y no se vieron piezas, o espacios más amplios, que pertenecían al conjunto, dando poca importancia al "lugar". Se hubiera debido confiar la misión a equipos pluridisciplinarios (arquitectos, antropólogos, geógrafos, arqueólogos, ...) sensibles a la complejidad de cada edificio.
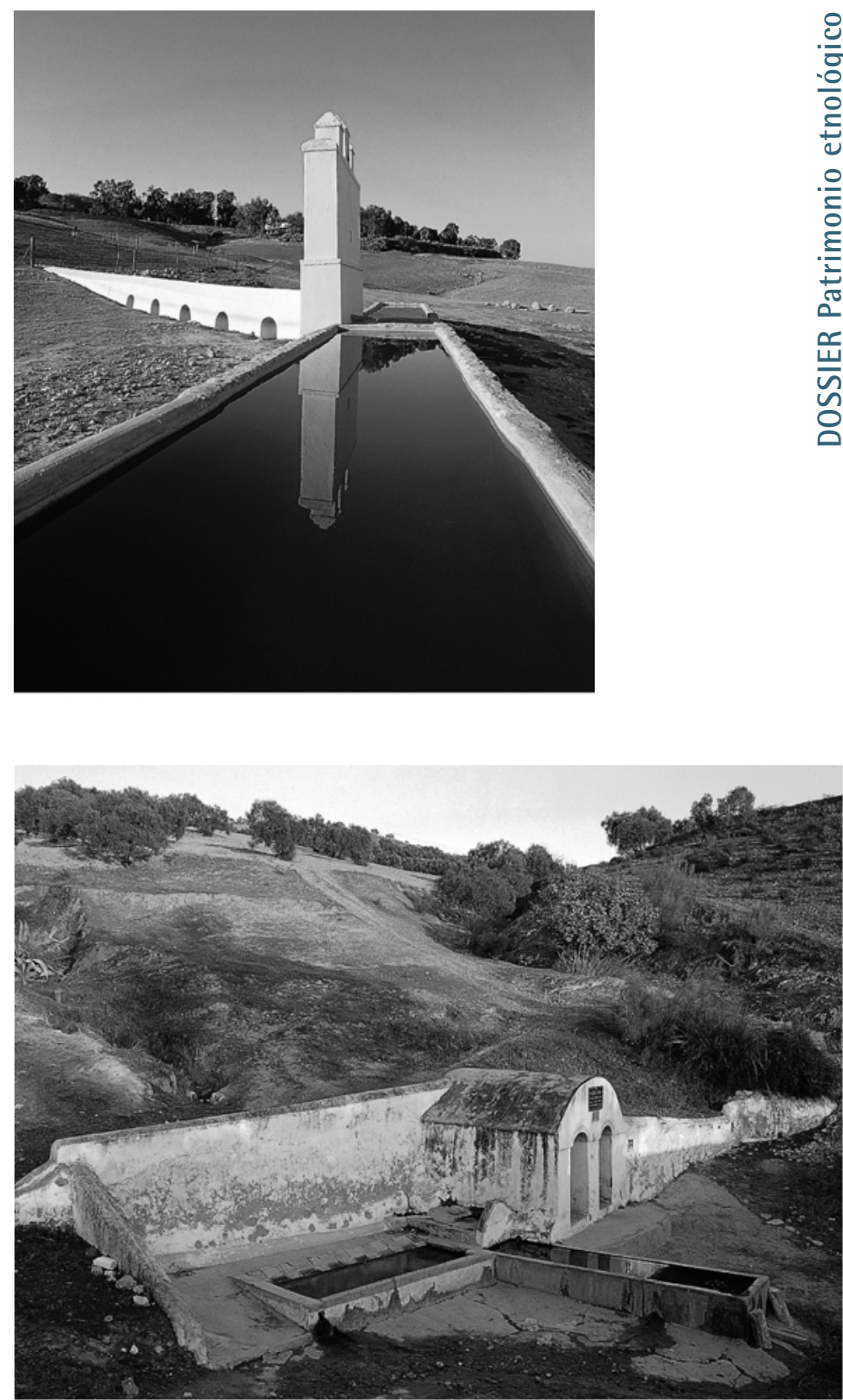

No creo que esto fuese la razón por la que no se inventariaron fuentes de capital importancia como pueden ser: la fuente Roya de Estepa, la fuente de la Reina en Fuentes de Andalucía, la fuente del Perejil o la de la Judía en Alcalá de Guadaira. Pero puede que sí el que la mayor parte de las que lo fueron, se inventariaran mediocremente. Pudiéramos imaginar que esto ocurrió con aquellas menos significativas, pero en verdad fueron las más complejas e importantes las que peor trato obtuvieron, algunas tan señaladas como las de Pegalajar, o Priego de Córdoba, son ejemplos de pobreza inventarial incomprensible8. Ni aún en los casos mejor catalogados, no se comprendió el lugar de sociabilidad que formaban, ni la importancia del sistema que originaban.
Fig. 4 El Pilar Ancho. Carmona.

Foto: Javier Andrada

Fig. 5 Fuente de la Mezquitilla. El Sancejo.

Foto: Javier Andrada 


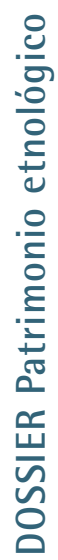
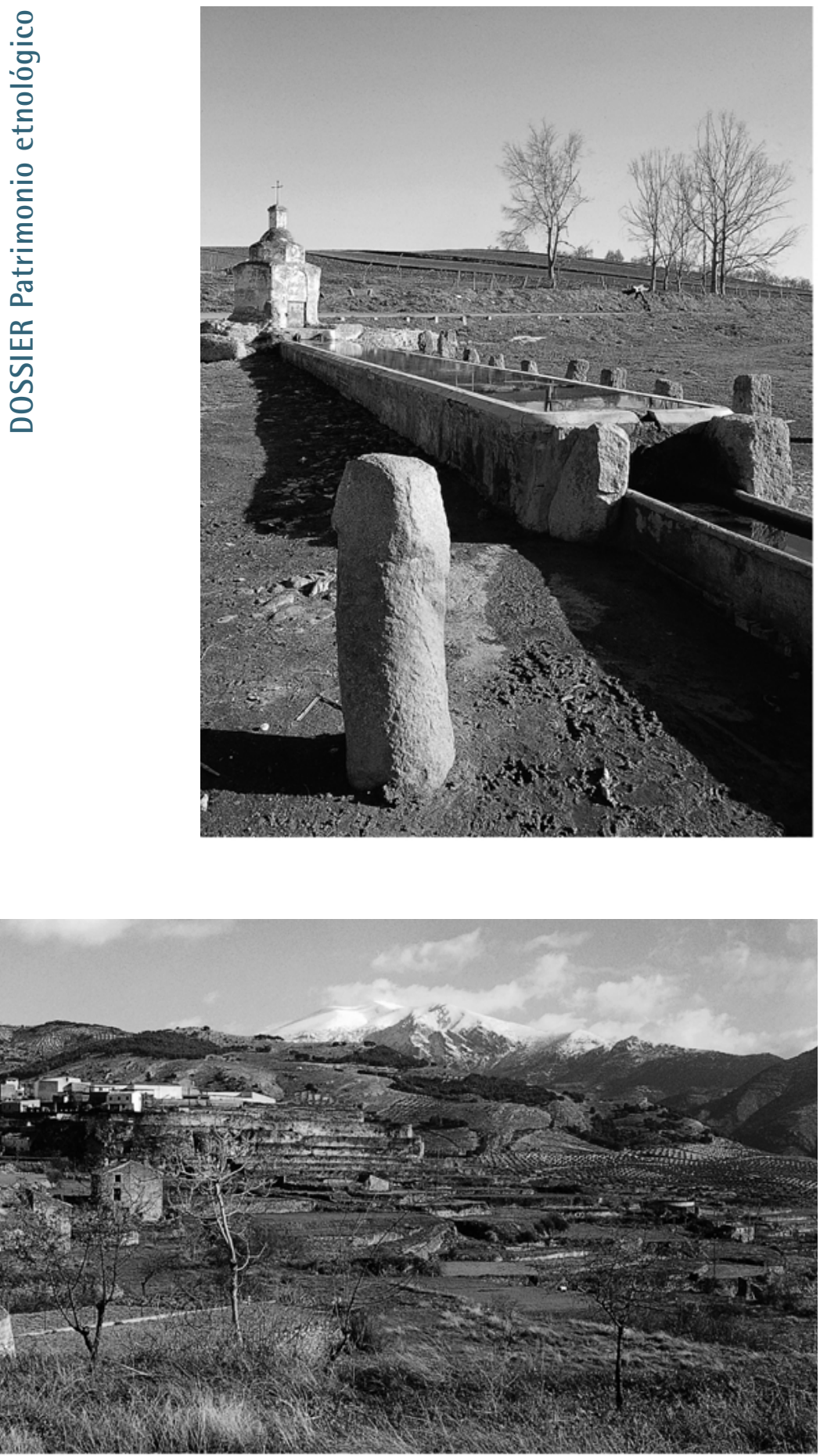

Fig. 6 Fuente de la Coriana.

Olivares.

Foto: Javier Andrada

Fig. 7 Aspecto actual de la Huerta de Pelagajar. Históricamente regada con las aguas de la Fuente de la Reja, embalsada y regulada en la charca.

Este entorno está catalogado como paisaje agrario singular en el Plan de Protección del Medio Físico, habiéndose solicitado su inscripción como "'Lugar de Interés Etnológico".

Foto: Diego Polo Aranda

\section{III}

Las restauraciones que se llevaron a cabo, en muchas ocasiones resultaron mediocres. Desde los pastiches suntuosos hasta los mamotretos tosco-camp(estres), no fueron diseñados para ser habitados sino más bien resultaron ejercicios gratuitos de mal gusto. No voy a citar aquí algunos por ser legión, que podéis encontrar por cualquier pueblo o ciudad andaluza, sin embargo, por su carácter paradigmático, sí señalaré dos muestras representativas de los casos en los que, por desgracia, se deformaron verdaderas joyas de la arquitectura hidráulica: las Pilas de Puebla de los Infantes, de época barroca, y la fuente renacentista de Martos. Las pilas de Puebla de los Infantes es uno de los casos más tristes e irrecuperables. El conjunto lo formaba una fuente pública que dejaba caer sus aguas a un lavadero, del que se vertía el sobrante por un ladrón a unas huertas. El recinto tenía unas proporciones ingeniosas, organizaba un espacio reducido para dar cabida a un mobiliario destinado a recibir un numeroso público. De factura elegante, procuraba al pueblo un lugar de encuentro y labor, sabio y bien proporcionado. La restauración ha saqueado el conjunto: se abrieron accesos nuevos, sin comprender la centralidad del primitivo que ofrecía una perspectiva despejada, se rebajó el nivel de los muros, se tapió el ladrón, se estrechó el pilón, se remplazó el ladrillo taco por chinos y cemento blanqueado, cuando el material primitivo procuraba una gama de ocres que cambiaba de matices según la hora del día. En definitiva se desfiguró el conjunto con pretensiones desafortunadas, confundiendo lo rústico con lo banal, utilizando sin recato ladrillo mal cocido, pedrusco y cal, paliando la falta de imaginación por el tópico: lo blanco es bello. Lo cierto es que ahora resulta un espacio estrecho, deshabitado y feo que bien puede terminar como papelera pública, o cagadero.

El caso de la Fuente Nueva de Martos es, de otro modo, paradigmático de lo que nunca se debe hacer por salvar unos "restos" valiosos. La fuente renacentista obra de Francisco del Castillo, construida en I538, no sólo abastecía a la población sino que servía de ornato y punto axial para la configuración de todo un barrio, a la entrada de la villa. Pieza monumental, ejemplo de la arquitectura del género, no podía ser demolida simple y llanamente para ampliar la red viaria. Con ocasión de una remodelación del acceso al casco antiguo, se desmontó y se trasladó a una avenida periférica, encajonada entre inmuebles de gran tamaño, se la rodeó de unos jardincillos nimios, se perdió la cabeza del águila que corona el escudo, se la amputó de buena parte del pilar, se la privó de agua, condenándola a la fosilidad y al enjaulamiento. Quedé sobrecogido cuando después de mucho buscarla la encontré desaliñada, achicada, sin función: como muda besania parecía mendigar su salvación o su holocausto. La sensación fue tal que no supe si la congoja me dejaría dirigir la queja a los responsables culturales del lugar, tanta era la rabia y el dolor. 
Llegados aquí os preguntareis, pero hubo alguna restauración buena? Haberlas hailas, aunque incompletas, por la dificultad que toda rehabilitación conlleva cuando no está acompañada de un proyecto social, pues no vale solamente con salvaguardar el edificio. Citaré como ejemplos hermosos el Pilar Ancho de Carmona que en el centro de un descansadero espera recibir el tráfago de hombres y ganados que hiciera su grandeza, los abrevaderos de Castilblanco de los Arroyos, la restauración que se está efectuando en la fuente del Rey de Priego, o la rehabilitación que Romain Gilbert proyecta para la fuente de la Albuhera, y su descansadero, en Aracena.

Cuando digo que no conozco alguna restauración completa es porque ninguna se pensó en función de la recuperación de un sistema? ${ }^{9}$. Hace algunas décadas se suprimieron los exvotos que a la Virgen de la Salud la gente ofrecía sobre el nacimiento de la gran fuente de Priego, el valor de la huerta, en franca decadencia, hace peligrar su existencia, sin embargo no creo que en la restauración que ahora se está efectuando se considere el recobrar la hornacina como lugar de culto o se prevea un porvenir al antiguo modo de riego. Lo mismo se podría decir de Alcalá de Guadaira que poseyendo uno de los conjuntos más completos de arquitectura del agua, que hubiese podido albergar el más original proyecto de ecomuseo, tan solo se piensa en la restauración de algún molino, sin saber muy bien qué función atribuirle, o en todo caso deshabitándolo, privándolo de agua y de sus usos sociales.

Galaroza, Priego, Alicún, Pegalajar, Fuenteheridos, Castril, Alcalá de Guadaira, (...) son numerosos los pueblos andaluces que vivieron por y para el agua. El agua les hizo, a ella le deben su cultura, su manera de sentir y pensar la vida, su antigua fortuna, sus formas de creer y de relacionarse, su goce y su trajín. Todos ellos tienen su espacio marcado por la hidráulica, las lievas ajustadas al terreno, presas, saltos, molinos, fábricas y un paisaje de huerta pueden leerse a pesar del abandono. Mas la mayoría han renunciado a ser con el agua. Es también cierto que pocos han conocido el sufrimiento de ver partir para siempre lo que fue su razón de existir, y aún menos los que hicieron de esta ausencia objeto de lucha y esperanza. Pegalajar es en esto ejemplar por no haber perdido ánimo y hacer de la ausencia la conciencia colectiva de un pueblo. La lucha por el acuífero se convirtió en un proceso de aprendizaje, que dinamizó proyectos de rehabitación de un lugar que los técnicos consideraban irremediablemente perdido.

Un manantial en la falda de una ladera árida dio lugar a una forma de cultivo heroica, donde el hombre llevó la tierra al agua, creo bancales de tosca, los llenó de tierra, canalizó y distribuyó sabiamente, cultivó y colectó. Con el remanente alimentó almazaras y fábricas, movió molinos, en definitiva creó riqueza entre riscos que solo servían de refugio.

La Fuente de la Reja o Fuente Vieja organiza un espacio complejo. Desde su cabecera una imagen sagrada preside el nacimiento, allí se construyó una ermita que le dio cobijo. Al manantial se descendía por unas gradas, hoy desaparecidas, para sacar lo necesario al uso doméstico. El caudal se acopia en un estanque de regulación, laguna que sobrecoge a quién sube por primera vez. La charca fue lugar de almacenamiento y de deleite. Además de alimentar el sistema, también servía como balneario para lugareños y forasteros, ir a tomar baños fue una de las actividades del estío; alrededor de la charca se faenaba y se gozaba.

Hacia abajo las acequias distribuían otras hijuelas para regar la huerta; una de las acequias madre surtía un la-
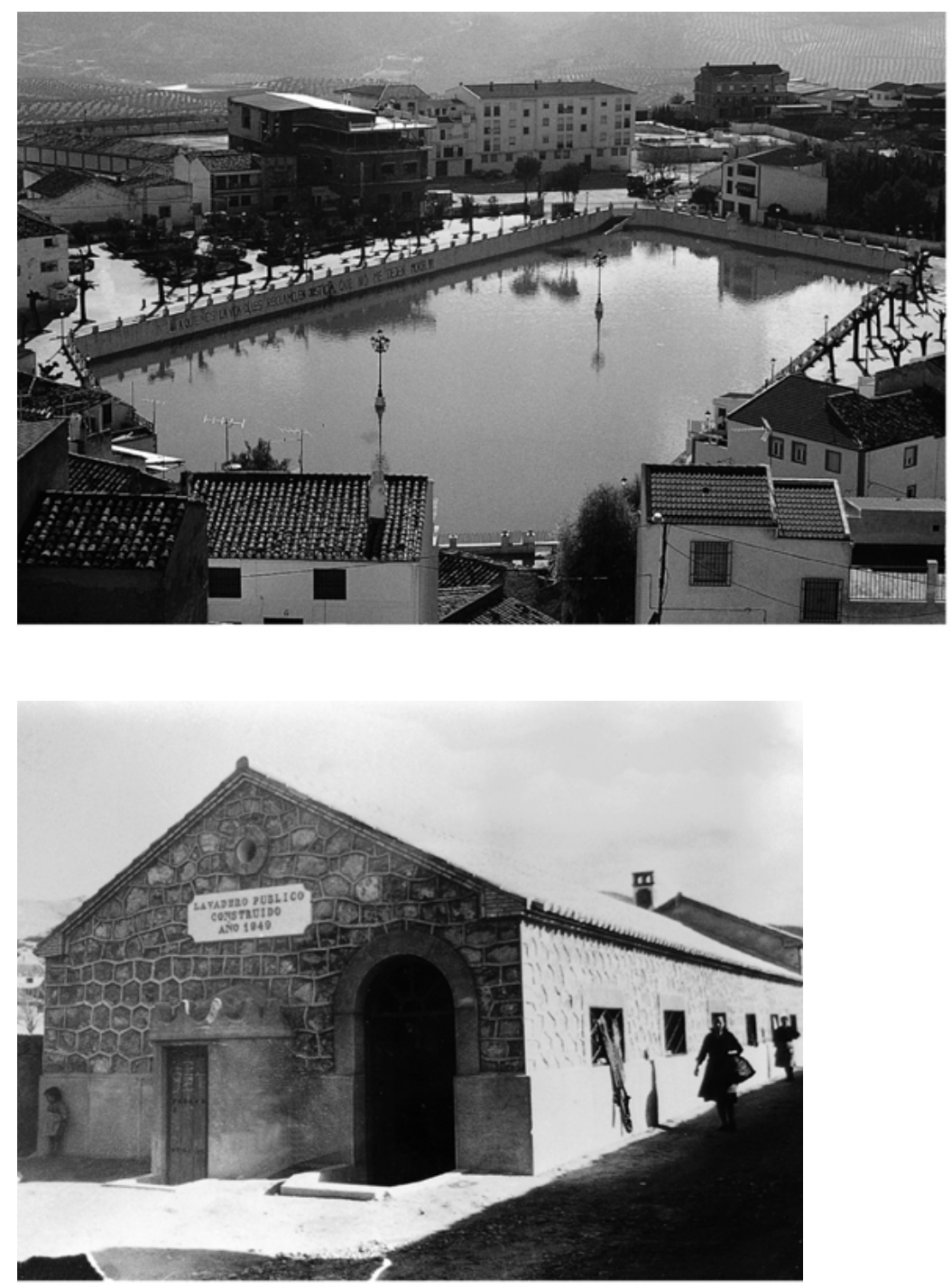

vadero, alimentaba una fábrica de jabón, proveía alguna almazara, y servía caudal a varios molinos.

Esta perfección de medios, esta ajustada economía del agua creó fecundidad y forjó la cultura de todo un pueblo.

Con la sobreexplotación del acuífero en tiempos de sequía, la fuente dejó de manar, la charca se secó, las acequias dejaron de funcionar y el sistema entero de Pegalajar. En el mes de enero empezó a recuperarse el Manantial de la "Fuente de la Reja", del que se surte Foto: Diego Polo Aranda

Fig. 9 Lavadero públlico de Pegalajar, construido en 1949. Ahora se pretende recuperar para integrar un interesante Museo del Agua

Foto: Archivo Diego Polo Aranda
Fig. 8 Aspecto actual de la Charca 
quedó como un esqueleto inútil sobre el que varios vertederos de alpechín ya presagiaban un futuro degradado y estéril.

A principios de los 90 , un movimiento ciudadano hizo de la lucha por el manantial un proyecto colectivo con miras a reanudar tradición y cambió en un proceso de lenta concienciación.

Hoy rehabilitar no es otra cosa que rehabitar, crear de nuevo un lugar de vida. Con el agua recobrada, se concreta un proyecto de ecomuseo, gestionado por una fundación que reúna instituciones, habitantes y agentes de la economía local. Su principal misión salvaguardar el acuífero, mostrar como se puede regular su raudal sin agotarlo, devolver al pueblo su razón de existir. Su principal idea, hacer de la fuente el foco que sirva de morada a lo divino y a lo humano, hacer de la charca un lugar de encuentro y recreo, verdadero espejo existencial de la comunidad. Su primer proyecto: crear un elemento central en los antiguos lavaderos que no sólo recoja los objetos dispersos de la cultura del agua, sino también ofrezca salas de reunión y trabajo, una mediateca-biblioteca que reúna documentos relacionados con aquella, un espacio de exposición polivalente, que permita el mantenimiento de los lavaderos y la instalación de diferentes manifestaciones ..., en definitiva un lugar de acción e investigación solidaria, un lugar para aprender y crear, para pensar, guardar, y tramar. El ecomuseo comprenderá así mismo dos molinos recobrados y parte de la huerta, donde no solo pondrán en funcionamiento un sistema de molienda y producción de harina agrobilógica, sino que se cultivarán frutos con los que elaborar productos de calidad. Un sistema inteligente de participación -la creación de pequeños núcleos de producción, escuelas talleres para la restauración y aprendizaje de técnicas artesanas-, empiezan a tomar cuerpo haciendo de esta rehabilitación un ejemplo de como se puede habitar un espacio, de como se pueden crear lugares en un mundo rural para el que sólo se pensó una muerte tranquila. Así este museo no será un embrollo de piedras restauradas, un amasijo de viejos utensilios polvorientos e inútiles, sino el despertar de toda una compleja cultura. De este colectivo podemos todos aprender la lección: rehabilitar implica recobrar razón de "ser", rehabilitar conlleva rehabitar, redimensionar la morada para dar acogida a la Cuaternidad; como escribía Heidegger: "Salvar la tierra, acoger el cielo, esperar a los divinos, guiar a los mortales, esta cuádruple facultad es la esencia simple de la habitación". (1994, p. 140)

\section{Notas}

I. Las referencias de página corresponden a la edición castellana, no así la versión del texto que me es personal.

2. Válgame la expresión como un juego cargado de sentido No se toma el discurso al pie de la letra sino en su contexto, cargado de un valor que le trasciende.

3. Es cierto que muchos edificios nunca tuvieron razón de ser y desde su nacimiento fallan en su capacidad de crear lugar.

4. Heidegger dice a propósito de un puente que es un lugar donde están admitidos cielo y tierra, los divinos y los mortales. (1994, p.136)

5. Citado por André Préau en una nota al pie de página de la traducción francesa: Essais et conférences. (p. 184)

6. Llegado aquí, me parece oportuno plantear otra pregunta: para quién están hechos los inventarios. Para la comunidad interesada, o para una mera justificación administrativa? A menudo reposan en legajos sin futuro o perfectamente archivados esperando el experto que los revele y utilice sin que los interesados los conozcan. La difusión que se reserva a un buen inventario puede ser fundamental para la permanencia de un edificio y de su espacio.
7. Las fichas que se manejan actualmente para la base de datos del Patrimonio Histórico de Andalucía son mucho más completas que las aquí consideradas ; siendo una de las más inteligentes de las que yo conozco, la que se utilizó en el inventario de los bienes patrimoniales del Guadiana, dentro del proyecto Almutamid, (proyecto inventario cuatro pueblos fronterizos). Pero a mi punto de vista lo más considerable y ejemplar fue que la misión recopiladora se confiara a un equipo pluridisciplinario.

8. Valga como ejemplo señalar que de la primera sólo se anotó la existencia de la charca y de la segunda se confunde el conjunto con las partes, obviando toda descripción y señalando como observación una nimiedad concerniente el número de caños.

9. El proyecto de Romain Gilbert puede sea un caso aparte, si llega a cuajar, por existir una visión de conjunto y por implicar a los responsables municipales en su "rehabitación".

\section{Bibliografía}

AUGÉ, M:

1995. Los "no lugares". Una antropología de la sobremodernidad. Barcelona.

\section{CANTERO MARTÍN, P. A.:}

1989. Reine des Anges, Dame des Eaux. Bordeaux.

1995. La arquitectura del agua. Sevilla.

1996. "Las fuentes de Sevilla". en: El Siglo que viene n² 28. Sevilla. (pp. 54-55)

GALDO, A. \& LINARES, F.J:

1996. "Pegalajar, mil años en extinción". en: e.a. Esfuerzo por Andalucía nI. Sevilla (pp. 17-26)
HEIDEGGER, M:

1994a. "Construir, habitar, pensar". en Conferencias y artículos. Barcelona. (pp. 127-|42). (I la ed . alemana 1954.)

1994b. "...Poéticamente habita el hombre". en Conferencias y artículos. Barcelona. (pp. 163-178)

LÓPEZ CORDERO, ।. A., LIETOR MORALES, J. \& ROJAS LÓPEZ, .: 1994. Pegalajar: Nueva aproximación histórica. Pegalajar.

W. A A.:

1988. Inventario de fuentes y surtidores públicos de Andalucía. Dirección General de Bienes Culturales. Consejería de Cultura. Sevilla. (Inédito)

1996/1997. Enteoría. Publicación periódica de Teoría de la Arquitectura. Sevilla. 